\title{
A Radical Take on Zombie Apocalypse: Dominic Mitchell's In the Flesh
}

\author{
Finch Byrd*, Comparative Literature
}

\begin{abstract}
Traditionally, the genre of zombie apocalypse has relied on a number of tropes: zombies' inhumanity, mindlessness, decaying bodies, and capability to create new zombies with their bite. These tropes stem from societal opposition to disability, as well as from fear of non-heteronormative reproduction and the Freudian death drive. Most zombie literature is not outwardly critical of these tropes, but instead plays on them to portray zombies as an ultimate horror, a type of being that is other than and inferior to humans, that can-and should-be killed indiscriminately to prevent the destruction of western society as we know it. However, one zombie narrative, Dominic Mitchell's BBC miniseries, In the Flesh, stands out above the rest as distinctly aware and radically critical of these tropes. In the series, the living majority's medicalization and re-terming of undeath as "Partially Deceased Syndrome" creates an allegory for disability. "Zombies" are given agency in the series, and the series' protagonist is a young, gay undead individual. Sentient and sympathetic zombies combined with notions of disability and queerness pose a radical challenge to the conventional (read: conservative) tropes of the zombie genre.
\end{abstract}

Dominic Mitchell's BBC miniseries, In the Flesh, is a radical take on the traditional zombie apocalypse genre. The show centers on Kieren Walker, a teenage boy and resident of the fictional village of Roarton, Lancashire, England. Kieren, according to the medical theory established in the show, suffers from Partially Deceased Syndrome (PDS)-that is, he is essentially a zombie, who arose from the dead during "The Rising." The Rising could be termed a zombie apocalypse: even though it did not entirely obliterate society, it resulted in widespread unrest, a struggle for survival, and fundamentally changed villagers' day-to-day lives. The show follows Kieren as he returns home from a rehabilitation center for PDS sufferers and differs from other zombie narratives because the main character is a zombie himself. Zombies in the show have agency, thus radically altering the conventional dynamics between zombies and non-zombies (henceforth, "the living").

*Finch Garland Byrd is in its third year at the University of Oregon. It is a student in the Robert D. Clark Honors College, is majoring in Comparative Literature with focuses in Philosophy and German, and will be minoring in Disability Studies after the program officially launches in Fall 2017. Finch is also interested in feminist, queer, post-structuralist, anarchist and leftist theory, modernism, postmodernism and surrealism. It is passionate about social justice, which, along with its own disabilities and experiences as nonbinary/transgender and bisexual, provides a theoretical framework for its writing. Please direct correspondence to finchb@uoregon.edu. 
As Sarah Juliet Lauro and Karen Embry reveal through their analysis of the figure of the zombie in "A Zombie Manifesto: The Nonhuman Condition in the Era of Advanced Capitalism," the zombie is a distinctly radical figure, based on the destruction of existing social models of power. However, no matter how much conventional representations of zombies may recognize this potential, and indeed some seem to-for example, in George A. Romero's Dawn of the Dead, zombies are representative of "...capitalist drone[s]"-none actualize it, because overall, the historical genre of zombie apocalypse is conservative. It champions the structures that the zombie exists to destroy (Lauro and Embry 87). In the average zombie apocalypse narrative, zombies are dehumanized: They are portrayed as a threat to individualism, as grotesque-that is, affirming the societal fear of disability and death, and as a threat to reproductive futurism as defined by Lee Edelman (2). Consequently, their progressive potential is staunched by unrelenting violence against them. Contrary to this conventional narrative, In the Flesh disapproves of the hatred and violence of the living, and portrays zombies sympathetically. In the Flesh challenges the tropes of the traditional zombie apocalypse genre: "Zombies" are given agency in the series and clearly defined as disabled individuals-they are diagnosed as "Partially Deceased Syndrome" (PDS) sufferers by their living counterparts, and choose the labels "undead" and "redeemed" for themselves. Furthermore, Kieren, the series' protagonist, is himself a young, gay PDS sufferer. Sentient, sympathetic zombies and notions of disability and queerness combine in the series as a radical challenge to the conservative tropes of the zombie apocalypse genre.

Lauro and Embry argue that by simultaneously occupying the states of life and death, or subject and object, the figure of the zombie disrupts traditional power dynamics:

[The zombie's] threat to stable subject and object positions, through the simultaneous occupation of a body that is both living and dead, creates a dilemma for power relations and risks destroying social dynamics that have remained-although widely questioned, critiqued, and debated-largely unchallenged in the current economic superstructure. (Lauro and Embry 90)

They draw upon the history of the zombie, beginning with the Haitian "zombi," which they argue is both representative of slavery and slave rebellion, another dual occupation of object and subject positions, and discuss how the zombi has been appropriated into western culture as the "zombie," a figure of endless consumption (98-99). However, Lauro and Embry also point out that while the western zombie is certainly a capitalist figure, it is yet again subject and object at once, in that it "...represents the new slave, the capitalist worker, but also the consumer, trapped within the ideological construct that assures the survival of the system" (99). The rise of zombies in western zombie apocalypse narratives can thus be seen as a workers' rebellion, but one that does not truly provide escape, just as the zombi's slave rebellion did not free the zombis from their bodies or object position. The zombie, according to Lauro and Embry, is inherently a radical figure. It has simultaneously occupied positions of oppression and rebellion both historically and contemporarily, enabling it to upend societal constructs of power.

Though Lauro and Embry make the radical potential of the zombie explicit, they also reveal the societal fear of this radicalism, which is intrinsically connected to capitalism, ableism (the 
societal marginalization and oppression of disabled people) and heteronormativity. Zombie apocalypse fiction is, of course, a horror genre, and so presents the zombie as something to fear; thus, traditional works of the genre display all the radical potential that Lauro and Embry point to in a distinctly negative light. As a result, the historical zombie apocalypse genre can be said to be generally conservative-i.e. interested in the preservation of present society's structures. Lauro and Embry's essay points to a number of tropes of the zombie genre that present the zombie in such a negative light. First, the zombie is a threat to individualism: Lauro and Embry note that "...fear heightens our awareness of ourselves as individuals because our individuality is endangered in life-threatening situations," and that the zombie's lack of consciousness and ability to spread that lack of consciousness by turning others into zombies exacerbates that fear (89). Lauro and Embry also mention that individualism is chiefly a capitalist imperative, that capitalism “...depends on our sense of ourselves as having individual consciousnesses to prohibit the development of a revolutionary collective and to bolster the attitude that drives it: every man for himself" (106). The traditional zombie apocalypse genre is highly profitable and thrives on the preservation of individualism in order to present zombies as something to be feared: To a paying audience in capitalist society, there is nothing more frightening than the prospect of losing one's individuality. Secondly, Lauro and Embry note the way zombies embody the societal fear of disability and death, saying that "[the] vulnerability of the flesh and the instinctual fear of its decay, as well as the dissolution of consciousness-all things that happen as we approach deathare suggested in the monstrous hyperbolic of the zombie as living corpse" (101). Lauro and Embry then go on to elaborate how zombies emulate the way society perceives the minds and bodies of the disabled, writing that "The mentally ill [sic] have historically been portrayed as having a consciousness that is morally suspect or a total lack of subjectivity," and that "Even the lumbering gait of the cinematic zombie, which probably is meant to reflect rigor mortis and advanced decay, looks like a muscular disorder" (103). It is not the simple emulation of mental and physical difference, or of closeness to death that elicits fear. Rather, the zombie apocalypse genre reaffirms the societal oppression of disabled people by not only portraying, but also by vilifying, mental and physical difference. Robert Bogdan et al. explain this in their essay, "The Disabled: Media's Monster," writing that "[by] linking ugliness and physical and mental differences with murder, terror, and violence, the media creates, at the same time as it perpetuates, society's prejudicesprejudices that result in fear of the handicapped [sic] and, ultimately, in their systematic, intentional exclusion from society" (32). Zombie apocalypse media does precisely what Bogdan et al. describe by portraying zombies, figures with physical and mental differences from the living (who are figured as "normal"), as inherently evil and worthy of fear. So, the zombie apocalypse genre is conservative in that it vilifies non-normative physical and mental states, thus affirming extant power structures wherein individuals who do not fit the normative mental/physical profile are disabled by society.

Finally, the zombie apocalypse genre also portrays zombies negatively, as a threat to reproductive futurism. Reproductive futurism, as defined by Lee Edelman, is the notion that children - the heteronormative ideal-are the future of humanity. This futurism defines politics and is in direct opposition to queerness, which represents the Freudian death drive. Edelman writes that: 
...politics, however radical the means by which specific constituents attempt to produce a more desirable social order, remains, at its core, conservative insofar as it works to affirm a structure, to authenticate social order, which it then intends to transmit to the future in the form of its inner Child. (2-3)

In the way that Edelman points out the heteronormativity, and thus conservatism, of politics, so too is the zombie apocalypse genre conservative for posing the zombie's threat to reproductive futurism as a decidedly negative, horrific scenario. In the traditional genre, heteronormative reproduction is defeated by a reproductive method that destroys, rather than ensures, the future of humanity. Lauro and Embry write, "[the] zombie's reproductive drive...is either an unconscious urge or a mere side effect of its own hunger, for it is through its bite that the zombie reproduces itself" (99). The horror of the zombie's reproduction is firstly that it does not create new life: it negates reproductive futurism by not producing children. Instead, already living people are transformed into zombies; the living are eliminated, thus ending their (generally, hetero-) sexual reproduction. Secondly, it is horrific in that the zombie's asexual reproduction is in fact more effective in creating sheer numbers than the living method of sexual reproduction. This disproves the efficiency of heteronormative reproduction for ensuring the future of humanity and enables an actual zombie apocalypse that overtakes society. Thirdly, zombie reproduction joins the reproductive drive with the death drive, what Edelman argues reproductive futurism works against, in that the reproductive drive of zombies eliminates the living and replaces them with figures of death. Just as the loss of individuality and the disability of zombies are vilified, the asexual reproduction of zombies is also presented as a horror. Thus, the genre affirms the present societal imperatives of individuality, the oppression of the disabled, and reproductive futurism. The biggest factor that informs this conservatism is the perspective of the genre, that is, the protagonists of the zombie apocalypse genre are not the ringleaders of the zombie apocalypseinstead, they fight against the zombie hordes for society's preservation. Almost all representations of zombies fall into these conservative tropes in one way or another. In some cases, the radical potential of the zombie may be acknowledged in some way (for example, positioning the zombies as “capitalist drones” in George A. Romero's Dawn of the Dead, as Lauro and Embry discuss), or the zombies may win at the end of the film. The politics of identification in the traditional zombie film, however, generally end with the audience positioned against the zombies. At some point in the typical narrative, the audience is inclined to identify with the zombies as they overtake rude, selfish, or generally unsavory characters. This moralizing role of the zombie is also decidedly conservative, however, and the fact remains that at the end of the traditional zombie film, there are still "good" humans worthy of viewer identification: the zombies remain the villains, positioned against the future of humanity. This politics of identification negates any possibility of radicalism or movement away from societal power structures.

In the Flesh, however, rejects most of the conservative tropes of its genre, and affirms the radical potential of the zombie that Lauro and Embry define. Most conducive to this effect is that the audience is made to identify with the "zombies" of the series, who are given agency. In fact, the "zombies" are given so much agency that they are not termed as "zombies" at all-in this paper, they will henceforth be referred to as "the undead," as this this is their preferred term in the show. 
Both "zombie" and "rotter" are used pejoratively and are akin to slurs in the show-"rotter" is used persistently throughout the series, and in Episode 1 of Season 2, Kieren teases his best friend, Amy Dyer, about having “...come back a zombie Buddha," only for her to recoil at the word, which, like "rotter," serves to dehumanize and vilify the undead. When he apologizes and substitutes "Partially Deceased," she exclaims, "That's even worse, that's the name the living gave us! We are the undead, we are the redeemed, got it?” Amy, at this point, has joined with the radical Undead Liberation Army (ULA), a sort of undead cult that operates under a model based off of Christianity-in which there is one "Undead Prophet" and 12 disciples-to offer an explanation for the Rising and to fight for the rights of the undead in a society poised against them. The viewer, however, has not been given much insight into the ULA's practices; in fact, what has been shown of them is decidedly unsympathetic to their cause. For example, at the beginning of the aforementioned episode, ULA affiliates terrorize a train full of people by taking a drug called "Blue Oblivion" and going "rabid," that is, returning to their unmedicated state in which they attack people for sustenance. So, as Amy corrects Kieren's language, the viewer is just as in the dark as he is, wondering why Amy has taken sides with the ULA. However, at the end of the episode, Amy's boyfriend and undead disciple, Simon Monroe, is introduced. From Simon's introduction forward, Kieren and the viewer are simultaneously exposed to the ways Kieren, Simon, and the other undead are oppressed in a society that caters to and normalizes the living. As the show further exposes Simon and his views, both Kieren and the viewer become sympathetic to him; that is, as Simon and Kieren become closer and eventually become romantically involved, the viewer, in a sense, shares Kieren's experience. As the series goes on, it exposes the cruelty of the living, too: The living's understanding of the undead's oppression does not advance, but Kieren's understanding-and simultaneously the viewer's-does. Proof of this is Kieren's living sister, Jem. If, after her initial trauma-induced hostility in Season 1, she seems standoffish, though perhaps willing to understand her brother, in Episode 4 of Season 2, she is downright hostile during dinner with her family and Simon. In the final episode, she is again poised to shoot Kieren just as she nearly did during the Rising. Only after disaster strikes does she admit that "[she needs] help," near the end of the episode. Most of the other living characters develop similarly, portrayed unfavorably as Kieren feels increasingly betrayed by his family and their friends. Thus, the agency of the undead, and the narrative unfolding from Kieren's perspective are essential. The show portrays the living's mistreatment of and violence towards the undead as unacceptable, contrary to the usual zombie narrative, in which the heroes are the living-the very people who kill the undead indiscriminately.

Another factor informing the radicalism of In the Flesh is the way it handles the issue of disability. Unlike traditional zombie media, which perpetuates the othering and oppression of disabled people by coding zombies as disabled via their physical and mental differences, then posing those differences as horrific, In the Flesh makes explicit reference to disability by medicalizing the condition of undeath, terming it "Partially Deceased Syndrome." Andrea Hollomotz, in her paper, "Disability, Oppression and Violence: Towards a Sociological Explanation," describes how people with mental or physical differences (what Hollomotz terms "impairments") are considered to be inherently "vulnerable" to violence due to their differences, but asserts that it is actually socially imposed disability, "...the disadvantage or restriction of 
activity caused by the political, economic and cultural norms of a society which takes no or little account of people who have impairments and thus excludes them from mainstream activity," that allows this violence to take place (Hollomotz 479). In In the Flesh, so-called "PDS sufferers" are considered inherently lesser by the society they exist in, which caters to living people: Repeatedly throughout the series, cruel treatment of the undead is excused with two primary claims. The first implies that the living have a greater right to exist than the undead by suggesting that the undead will destroy humanity if they are not killed. Alex, an undead individual at the PDS treatment center in Episode 1 of Season 1 perhaps says it best, to Kieren: "If you hadn't of fed on [a living woman], you would have rotted away yourself. You shouldn't feel guilty," and when his response is met with a sigh from the counselor leading the group, he says, "What? They killed us too, during the Rising. They blew our heads off without a second thought. Oh, now, that's defending humanity. That's okay, that's not murder. That's- That's being a hero! While they get medals, we get medicated." The second claim is that the undead cannot feel anything and are not real people, so therefore killing them is acceptable. This is made clearest in Episodes 3 and 5 of Season 2. Maxine Martin, Roarton's Member of Parliament (MP) and representative of the pro-living party, Victus, uses laws to make the undead second-class citizens and excuse cruel treatment of them by reinstating the Human Volunteer Force (HVF), an army of living volunteers that Jem belongs to, which kill many undead both during and after the Rising. After Martin's laws are introduced, Kieren cannot leave the country, the undead are forced to work under the "Giving Back Scheme," and any progress that Roarton made in accepting the undead is effectively staunched. The substantial effect of Martin's laws on limiting the undead's societal reception and ability to function normally in society demonstrates how, as according to Hollomotz, disability is a social condition.

While In the Flesh clearly understands that zombies are a figure representative of disability, the way the show deconstructs the genre's traditional demonization of those who do not meet societal standards for mind and body does not end with mere acknowledgement of the genre trope. Rather, the Undead Liberation Army-and particularly the character of Simon Monroerepresent a disability rights movement poised against the pathology paradigm of disability. As disability rights advocate Lydia Brown writes in their article, "The Crisis of Disability is Violence: Ableism, Torture, and Murder," under the pathology paradigm, "[any] deviation from [the singular, normative template for human existence] is evidence of deficiency, defect, or disorder, and must be ameliorated, hidden, or eliminated altogether" (33). Rejecting the pathology paradigm, then, upends the social construction of the normative mind and body in a way that grants agency to all bodies, and indeed this is what the ULA does by rejecting both professional medication as well as the makeup and contacts undead individuals are expected to wear to fit in. In Episode 3 of Season 2, Kieren is forced under the Give Back Scheme to work with Simon in a PDS clinic, where he witnesses employees mistreating a couple of so-called "rabids." Simon, operating against the pathology paradigm, intends to set them free, but Kieren stops him, feeling that they are a danger and should receive treatment. Later in the episode, however, the incident seems to change Kieren's mind: He prevents another undead man, Freddie Preston, from being shot after he forgets to take his medication and subsequently becomes rabid. Inspired by Simon, Kieren sees Freddie not as a problem, but instead as somebody who deserves to exist, and so gives 
him a chance to live. Thus, rejection of the pathology paradigm grants agency to those who are unmedicated and refuse the societal imperative for assimilation. Furthermore, not categorizing individuals' bodies and minds as "abled" or "disabled" effects the destruction of the categories themselves, and thus begins an end to the oppression of disabled people: If there is no normative mind/body, there is no "other," and no accommodation is considered a "special need." In this sense, while Lauro and Embry assert that the zombie is a distinctly negative figure, whose radical potential lies only in its ability to destroy existing systems, characters in In the Flesh do mobilize positive political strategies-most notably coalition-building in the case of the ULA-to further their goals, which are ultimately negative: the destruction of the living's power over the undead as embodied by the medical-industrial complex. By being aware of and making obvious the trope of disability in the zombie apocalypse genre, as well as by dismantling the pathology paradigm of disability, In the Flesh disrupts the social system of devaluing and disabling the physically and mentally different.

A third way the series might be considered radical is through its embrace of the rejection of reproductive futurism. The rejection of reproductive futurism, as discussed previously, is another hallmark of the traditional zombie apocalypse genre. However, the genre traditionally vilifies the zombie hordes' asexual reproduction, furthering of the death drive, and subsequent rejection of reproductive futurism. In the Flesh, conversely, glorifies this rejection: Neither sexual nor asexual reproduction occurs in the series-Season 1, Episode 2 disproves the undead's ability to reproduce via bite, and sexual reproduction simply does not occur in the show. Furthermore, the few children that do appear in the series are either very minor characters, quickly killed, or deceased for the duration of the show. In Season 2, Episode 1, Ken Burton, Kieren's former neighbor, and the child with him (relation unknown) die in a undead terrorist attack; in Episode 2, Jem shoots and kills 16-year-old Henry Lonsdale; and in Episode 6, the long-awaited second Rising doesn't happen, much to the dismay of MP Martin, who was hypocritically hoping for the resurrection of her child brother. The few children that do survive (teenagers) are perhaps the future of Roarton, but an unfavorable one; the classroom scenes in Episode 2 of Season 2 make clear that they are being instilled with the dehumanizing ideas that oppress the undead. As the show aligns the viewer with Kieren and the other undead, if the high school children are a representation of reproductive futurism, they are a distinctly negative one. Additionally, Kieren himself is gay, and the two most developed relationships in the show are between two men-Rick and Kieren, then Simon and Kieren-who express no interest in creating a family. Heterosexual relationships in the show take one of three forms: strife-stricken (as with Kieren's parents, as well as with Bill and Janet Macy and with Freddie Preston and his former wife), a pairing of HVF members and thus a dangerous alliance (as with Jem and Gary), or else ending when one partner dies (as with Ken Burton's widow), suggesting that heterosexual relationships (and thus, heterosexual reproduction) are not viable in the show's diegesis.

While In the Flesh is radical in the sense that it counters the conservative tropes of the zombie apocalypse genre, its ideology is not wholly radical. The most glaring contradiction to its seemingly radical sentiment is the character of MP Maxine Martin, the only person of color who plays a major role in the narrative. Martin is hell-bent on eradicating the undead from Roarton, 
but also has a secret agenda that aligns with the Undead Liberation Army's: to cause the second Rising by killing the first risen of the undead, and to consequently revive her little brother. In the final episode of the show, she does go through with her plan, but presumably kills the wrong person, as the second Rising does not occur-though it remains unclear whether it would have happened regardless. The victim is a beloved friend of Kieren's, and tragedy strikes the show's protagonists. By making one of the few people of color in the show such a blatant villain, operating on her own selfish principles, the show vilifies people of color, perpetuating the social system of racism. Furthermore, the chatter near the end of the episode about MP Martin possibly having been committed (to a mental institution) potentially negates much of what the rest of the series does to work against the demonization of disability by suggesting that murderers are just mentally disabled, when in fact, disabled people are far more likely to be the victims of violence than the perpetrators of it (Hollomotz 478, Insel). While certainly not offering an excuse for this contradiction, Lydia Brown's article offers something of an explanation when they write: "Even in otherwise progressive and radical spaces, ableism is allowed not merely to proliferate, but to prosper...as though one set of marginalized identities is worthy of empowerment and validation and another can simply be discarded as undesirable" (33). Although Brown refers here to the vilification of disability, it is possible that in a narrative so concerned with disability, justice, and queerness that people of color would be the scapegoat on which oppression is blamed. Brown offers no explanation for why such scapegoating occurs, but the simplest explanation is that it is easier to blame any sort of oppression on another oppressed group than it is to wrestle with the larger systems that perpetuate it-for example, capitalism. That is, because capitalism-and all kyriarchy-is so engrained and naturalized in the collective consciousness, the course of least resistance is to pick a party to blame for oppression, rather than confronting, analyzing, and offering alternatives to the systems themselves. One real-world example of this is seen in the presentation, "The Trouble With Transgender," written by influential radical feminist Cathy Brennan (alias "Badhbh Catha"). In the text, she argues that the process of gender transition supports capitalism, because "Acquiring stuff, whether it be clothes or makeup or actual body parts, is essential to transgenderism." Thus, in Brennan's view, "Transgenderism as an ideology fits into capitalism perfectly" (Catha). What Brennan does here is scapegoating: She blames transgender people in particular for enabling capitalism, failing to realize that every action by anyone living in capitalist society is ensnared in the economic system. Capitalism itself makes "acquiring stuff" "essential" to anybody. This is how it persists; even a cursory analysis of the system would tell Brennan that, but real analysis is too difficult-it is much easier to put the blame on members of an oppressed group who are forced to pay for their very survival. Brennan's argument-and potentially the treatment of MP Martin in the show-is a reactionary response guised as radical, allowing oppression to continue under the pretense of abolishing it.

Another consideration is that the series' representation of queerness-particularly Kieren's sexuality and relationships-may not disrupt heteronormativity as much as it seems to. Thomas Crisp, in his essay, "From Romance to Magical Realism: Limits and Possibilities in Gay Adolescent Fiction," argues that "...many titles [of gay young adult literature] rely upon homophobia and homophobic discourse to provide readers with a sense of "realism," and that doing so "...simultaneously implies that homophobia is too large an issue to confront and is ultimately bad, 
but inevitable behavior" (339). Crisp argues that these works ultimately affirm heteronormativity by normalizing homophobia. In the Flesh seems to do this: In Season 1, Episode 2, Kieren faces homophobia, first from Gary, who makes a joke about "lezzes" (lesbians, derogatorily) at the school Amy attends, and tells Kieren that he should have gone there too, because he'd "...fit right in [because of his sexuality]." Amy seems disgruntled, but does not confront Gary's joke, and Rick, Kieren's former boyfriend, laughs at the joke, presumably so as to not mark himself as gay. Secondly, Kieren faces homophobia from Bill Macy, Rick's father. Bill is in denial about many aspects of his son's identity-he refuses to acknowledge that he is undead, and through Rick and Kieren's conversations in the same episode, it is revealed that the two hid their relationship, presumably because Bill did not accept his son's sexuality. Episode 3 of Season 1 provides further evidence for this: When Bill refers to Amy as Kieren's "girlfriend," Rick begins to speak up, but is cut off as his father orders him to kill Kieren for his defense of the undead. Later in the episode, even as Rick removes his contact lenses and cover-up and refuses to kill Kieren, asserting that he is undead as well, he disguises the romantic nature of his relationship with Kieren, only referring to him as his "best mate." Bill, apparently convinced that Rick is not his real son, kills him and leaves his body outside of Kieren's house. After finding Rick's body, Kieren comes to Macy's house and while condemning Rick's murder, asserts that Bill's dislike for him stems from his homophobia. As Macy realizes what he has done and leaves the house, Ken Burton kills him, but not for his homophobia-rather, as revenge for killing Burton's wife in the pilot episode and for his general hatred for and mistreatment of the undead. After Episode 3, though, the show never readdresses the issue. Kieren moves on, eventually meets and dates Simon, and nobody objects to their relationship-at least not on the grounds that they are of the same gender. In this sense, In the Flesh recapitulates the scenario that Crisp identifies: Homophobia is a natural part of Kieren's life; he must simply steel himself and overcome it on a personal level. Even though Bill, the main source of homophobia, is ultimately removed from the equation, homophobia in the series others Kieren's sexuality for the sake of the realism noted by Crisp. In this way, the series reasserts heterosexuality as a norm.

Finally, despite all its radical ideals, the series simply does not provide a solution: At the final bar scene, the living reveal that they are still disgusted with the undead, and the undead reveal that they are disgusted with the living. Though the show certainly disrupts the conservative premises of its genre and offers a radical version of the zombie apocalypse, nothing destroys the oppressive social systems within the show's diegesis; radical change never occurs. Perhaps this is because the undead of the show cannot get past their individuality; that is, they are too much subject, in Lauro and Embry's terms - the biggest example of this is when Simon breaks away from the radical ULA to protect and be with Kieren. Thus, while the show is certainly radical in comparison to others of its genre, it is not completely radical in the way that it leaves conventional power structures intact at the end of the series. The series, however, opens a new chapter in the history given by Lauro and Embry; it embraces the radical potential of the undead instead of presenting it as a horror. 


\section{ACKNOWLEDGMENTS}

I'd like to thank Professor Shoop and my dear friend Hayden Ygartua for their continued support in writing this paper and invaluable constructive criticism. I could not have completed this paper without them.

\section{REFERENCES}

Bogdan, Robert, et al. "The Disabled: Media's Monster." Social Policy, vol. 13, no. 2, 1982, pp. 32-35.

Brown, Lydia. "The Crisis of Disability Is Violence: Ableism, Torture, and Murder." Tikkun, vol. 29, no. 4, 2014, pp. 31-33. EBSCOhost, doi:10.1215/o8879982-2810074.

Catha, Badhbh [Cathy Brennan]. "The Trouble With Transgender - Presentation At Radfem Reboot.” 3 August 2012. Bugbrennan. www.bugbrennan.com/2012/08/03/the-troublewith-transgender-presentation-at-radfem-reboot/.

Crisp, Thomas. "From Romance To Magical Realism: Limits And Possibilities In Gay Adolescent Fiction." Children's Literature In Education, vol. 40, no. 4, 2009, pp. 333-348. Academic Search Premier, doi:10.1007/s10583-009-9089-9.

Edelman, Lee. No Future: Queer Theory and the Death Drive. Duke, 2004.

Hollomotz, Andrea. "Disability, Oppression and Violence: Towards a Sociological Explanation." Sociology-The Journal Of The British Sociological Association, vol. 47, no. 3, 2013, pp. 477-93. SAGE Journals, doi:10.1177/o038038512448561.

Insel, Thomas. "Understanding Severe Mental Illness.” NMH, National Institute of Mental Health, 11 January 2011. www.nimh.nih.gov/about/director/2011/understanding-severemental-illness.shtml.

In the Flesh. Writ. Dominic Mitchell. BBC, 2013.

In the Flesh: The Complete Season Two. Writ. Dominic Mitchell, John Jackson, Fintan Ryan. BBC, 2014.

Lauro, Sarah Juliet, and Embry, Karen. "A Zombie Manifesto: The Nonhuman Condition in the Era of Advanced Capitalism." Boundary 2: An International Journal of Literature and Culture, vol. 35, no. 1, 2008, pp. 85-108. EBSCOhost, doi:110.1215/01903659-2007-027. 